\title{
Sınıf Öğretmenliği Alanında Yapılan Lisansüstü Tezlerin İncelenmesi
}

\author{
Analysis of Postgraduate Theses in the Field of Classroom Teaching
}

\author{
Aylin YAZICIOĞLU1, Galip GENÇ²
}

\begin{abstract}
Öz
Bu araştırmanın amacı, 2015 ve 2020 yılları arasında sınıf öğretmenliği anabilim dalında yapılan lisansüstü eğitim tezlerini incelemek ve bu tezlerle ilgili genel bir çerçeve sunmaktır. Çalışma nitel desende oluşturulmuş, veriler Ulusal Tez Merkezi'nden alınarak toplamda 744 tez incelenmiştir. Verilerin analizinde doküman incelemesi kullanılmıştır. Sınıf öğretmenliği ile ilgili lisansüstü tezler; hazırlandığı yıllara, araştırmacı cinsiyetine, bilim dalına, lisansüstü düzeyine, çalışma yapılan gruplara, veri toplama araçlarına, veriler için kullanılan analizler değişkenlerine göre analiz edilmiş, her bir değişkene ilişkin yüzde ve frekans değerleri belirtilmiştir. Araştırmada incelenen tezlerin \% $86,6^{\prime} l 1 k$ bölümünü yüksek lisans, \%13,4'lük kısmını ise doktora tezi oluşturmaktadır. Tezlerin üniversitelere göre dağılımı incelendiğinde; 51 üniversitede yüksek lisans tezinin, 14 üniversitede doktora tezinin yapıldığı görülmektedir. Çalışmada incelenen tezlerin çalışma gruplarına bakıldığında "okul öncesi, ortaokul, lise, öğretmen adayları, özel eğitim öğrencileri" ile daha fazla çalışmanın gerçekleştiği bulgusu elde edilmiştir. Çalışma sonuçları incelendiğinde; doktora programlarının sayısının arttırılabileceği, özellikle yüksek lisans tez çalışmalarında karma yöntemlere ağırlık verilebileceği, ele alınacak analiz yöntemlerinde daha ileri istatistiki yöntemler kullanılabileceği getirilen öneriler arasında yer almıştır.
\end{abstract}

Anahtar Kelimeler Sinıf öğretmenliği Lisansüstü tezler Doküman incelemesi

\footnotetext{
Abstract

This research aims to analyze the postgraduate theses made between 2015 and 2020 in primary school teaching and provide a general framework for these theses. The study was created in a qualitative design, and a total of 744 theses were examined by taking the data from the National Thesis Center. Document analysis was used in the analysis of the data. Postgraduate theses on classroom teaching; It was analyzed according to the years it was prepared, the gender of the researcher, the science branch, the graduate level, the groups in which the study was conducted, the data collection tools, the analysis variables used for the data, and the percentage and frequency values for each variable were specified. $86.6 \%$ of the theses examined in the research are master's and $13.4 \%$ of them are doctoral theses. When the distribution of theses according to universities is examined; It is seen that master's theses were made in 51 universities and doctoral theses were made in 14 universities. When the study groups of the theses examined in the study were examined, it was found that more studies were carried out with "preschool, secondary school, high school, teacher candidates, special education students". When the results of the study are examined; It was among the suggestions that the number of doctoral programs could be increased, that mixed methods could be emphasized especially in master's thesis studies, and that more advanced statistical methods could be used in the analysis methods to be discussed.
}

Keywords

Classroom teaching

Postgraduate theses

Document review

\begin{tabular}{lll}
\hline Başvuru Tarihi/Received & Kabul Tarihi /Accepted \\
25.04 .2021 & | Araştırma Makalesi / Research Article $\mid$
\end{tabular}
29.11.2021

Suggested APA Citation/Önerilen APA Atıf Biçimi:

Yazıcıoğlu, A. \& Genç, G. (2021). Analysis of postgraduate theses in the field of classroom teaching. Manisa Celal Bayar University Journal of the Faculty of Education, 9(2), 1-14. https://doi.org/10.52826/mcbuefd.927793.

\footnotetext{
1 Sorumlu Yazar, Dr. Öğr. Üyesi, Karamanoğlu Mehmetbey Üniversitesi, Eğitim Fakültesi, Temel Eğitim Bölümü, Karaman, TÜRKIYE; https://orcid.org/0000-0003-3527-6982

${ }^{2}$ Dr. Öğr. Üyesi, Aydın Adnan Menderes Üniversitesi, Eğitim Fakültesi, Temel Eğitim Bölümü, Aydın, TÜRKIYE; (iD https://orcid.org/0000-0003$\underline{2447-4844}$
} 


\section{GİRIŞ}

Modern çağın gereksinimlerinin ve bilime verilen önemin daha da artmasıyla birlikte bilimsel araştırmalara yönelik gösterilen ilgi de giderek yükselmiştir (Terzi, 2005). Bilimsel çalışmalara gösterilen bu artışla birlikte bilimin kendi doğasında var olan yapı da yeni fikirlerin, düşüncelerin, deneylerin, çabaların, bilim insanlarının ve bilimsel çalışmaların gelişmesini, değişimini ve yeniden yapılanmasını sürekli bir hale getirmiştir. Yaşanan bu gelişim ve değişimler Türkiye üzerinde de etkisini göstererek özellikle 1950'li yıllardan itibaren toplum tarafından yükseköğretime olan ilginin ve talebin artmasını sağlamıştır. Yükseköğrenimde eğitim görmenin etkisi ve önemi, toplum tarafından da önemli görülmekte ve lisans eğitiminin kabul edilebilirlik oranının yüksek olması benzer nitelikte lisansüstü eğitim alanında da önemli gelişmelerin yaşanmasına etki etmiştir (Bıkmaz, Aksoy, Tatar \& AtakAltınyüzük, 2013). Gelişen süreç içinde ülkemizde üniversite sayılarında görülen artışla birlikte, lisansüstü tez ve araştırmaların yapılmasına yönelik çeşitli çalışmaların gerçekleştirildiği ve düzenlemelere gidildiği görülmüştür. Bu konuda 1959 yılında çıkarılan 7334 sayılı yasayla birlikte kurulan akademik birimlere lisansüstü eğitim ve araştırma yapma görevi verilmiş, 1981 yılında çıkarılan 2547 sayılı yasa ile de lisansüstü eğitimde yüksek lisans, doktora, tıpta uzmanlık ve sanatta yeterlik eğitimlerini kapsayacak şekilde yeniden düzenlemelere gidilmiştir (Sağlam, 2007; Bıkmaz vd., 2013). Akabinde meydana gelen 1992 ve 2006 yılıyla birlikte üniversite sayılarının hızla artması neticesinde de lisansüstü eğitim programları altında yeni programlar açılmaya başlamıştır.

Yeni bilim dallarının ortaya çıkmasıyla birlikte açılan akademik birimler; bilim ve tekniğin ilerlemesini sağlamak, araştırma ve öğretim yapmak, ülke sorunlarına çözüm yolları önermek, toplumun gereksinim duyduğu yüksek nitelikli insan gücünü yetiştirmek, yayın yapmak gibi işlevlere sahip olmaya başlamıştır (Karakütük, 2009; Şahin, Calp, Bulut \& Kuşdemir, 2013). Son yıllarda ülkemizde üniversite sayısındaki artış lisansüstü eğitime yönelimde de talebin artmasını sağlarken pek çok bilimsel araştırmayı da beraberinde getirmiştir (Özenç \& Özenç, 2013). Bu anlamda hazırlanan yüksek lisans ve doktora tezleri, lisansüstü eğitim programlarının en önemli bilimsel çıktıları olarak görülmüştür. Lisansüstü eğitim programlarının çerçevesi zamanla daha da genişleyerek eğitim boyutuna da etki etmiş̧, temel eğitim bölümü içinde yer alan sınıf öğretmenliği alanında da tezlerin hazırlanmasına ve sınıf öğretmenliği alanında pek çok boyutun, (değişkenin, yeni modellerin, yöntemlerin ve kaynakların) eğitim açısından incelenerek literatüre katılmasına olumlu bir ivme kazandırmıştır. Dolayısıyla yazılan bu tezlerin hazırlanma amaçları, araştırma süreçleri içinde yer alan bilimsel başlıklar, değerlendirilme yöntem ve kriterleri de giderek önem kazanmıştır.

Zaman içerisinde alanyazında yer alan bu çalışmaların genel bir değerlendirilmesinin yapılması hem geçmiş araştırmaların niteliğine dair bilgi vermiş hem de gelecekteki araştırmalara 1şık tutmuştur (Erdem, 2011; Küçükoğlu \& Ozan, 2013). Bu bağlamda literatür incelendiğinde "Sinıf Öğretmenliği" alanında hazırlanan tezlerin irdelenmesine yönelik olarak; Özenç ve Özenç (2013), 2010-2011 yılları arasında sınıf öğretmenliği ile ilgili yapılan tezleri incelenmiştir. Diğer bir çalışma olan Şahin vd. (2013) ise 2005 ve 2010 yılları arasındaki sınıf öğretmenliği alanındaki tezleri değerlendirmiştir. Bir başka çalışma da Küçükoğlu ve Ozan (2013) tarafından gerçekleştirilmiş, araştırmada 2008-2012 yılları arasında sınıf öğretmenliği alanındaki tezlerin ele alındığı görülmüştür. İlgili çalışmalara bakıldığında; sınıf öğretmenliği ile ilgili lisansüstü tezlerin hazırlandığı yıllara, araştırmacı cinsiyetine, bilim dalına, lisansüstü düzeyine ve ele alındığı araştırma desenine göre değerlendirildiği bulguları elde edilmiştir. Bunun yanında çalışma grupları, veri toplama araçları, kullanılan analizler de incelenen ögeler arasında yer almıştır. Belirtilen çalışmalarda da görüldüğü gibi lisansüstü tezler ile ilgili yapılan araştırmaların sınırlı sayıda gerçekleştirildiği dikkati çekmiş̧ir. Aynı zamanda bahsi geçen çalışmaların dikkate aldıkları değişkenlerin de sınırlı olduğu göze çarpan noktalar arasında yer akmıştır. Bu yüzden bu araştırma ile beş yıl içinde yapılan lisansüstü tezler incelenerek bu tezlere ait oluşturulan 11 adet başlıkla değerlendirilmeye çalışılmıştır. Böylece, farklı değişkenleri dikkate alan ve geniş bir zaman dilimindeki araştırmaları inceleyen bu çalışma ile alanyazına katkı sağlanmaya çalışılmıştır. 
Bu bağlamda yapılan bu araştırma ile Türkiye'de sınıf öğretmenliği alanındaki hazırlanmış tezlerin incelenmesi, bu tezlerle ilgili genel bir çerçeve sunulması çalışmanın başlıca amacını oluşturmuştur. Çalışmayla birlikte sınıf öğretmenliği alanında yapılan tezlerle ilgili genel bir değerlendirme yapmak, incelenen tezlerin araştırma süreçlerine ilişkin çeşitli başlıkları irdelemek ve alanyazına kazandırmak ele alınan diğer amaçlar arasında yer almıştır. Hazırlanan tezlerle ilgili yapılan analizler sonucunda elde edilen bilgilerin gelecekteki araştırmacılara; çalışma konusu, yöntem, örneklem seçimi, veri toplama süreci-kaynakları ve uygulanan analiz boyutları hakkında genel bir çerçeve çizmesi alanyazın için kazandırılması umulan önemli noktalardan biri olarak görülmüştür. Hedeflenen amaç ve önem doğrultusunda; son yıllarda oluşan değişikliklerin görülmesi ve güncel çalışmaların irdelenmesi açısından 2015 ve 2020 yılları arasında sınıf öğretmenliği anabilim dalında yapılan lisansüstü eğitim tezleri aşağidaki kriterlere göre incelenmiştir:

1. Düzeyleri (yüksek lisans/ doktora),

2. Araştırmacılarının cinsiyeti,

3. Hazırlanan üniversite,

4. Bilim dalları (Doçentlik bilim dallarına göre),

5. Danışman unvanları,

6. Hazırlanan yıl,

7. Uygulanan siniflar

8. Kullanılan yöntemler

9. Örneklem/çalışma grupları

10. Kullanılan veri toplama araçları

11. Uygulanan analiz yöntemleri

\section{YÖNTEM}

Sınıf öğretmenliği alanında yapılan lisansüstü tezlerin incelenmesine dayalı bu araştırma nitel anlayışa göre desenlendirilmiştir. Nitel araştırma anlayışında; daha önceden çalışılmayan ya da çalışılan konuyla ilgili bilginin az olduğu durumlarda daha fazla bilgi edinmek, araştırılanın gözüyle bakmak, olay, durum, norm ve değerlere ilişkin yeni bir bakış açısı geliştirmek amaçlanmıştır (Bryman, 2006; Creswell, 2008). Buradan hareketle, sınıf öğretmenliği alanında lisansüstü tezlerin incelenmesine dayalı olarak alan yazında sınırlı sayıda çalışmanın olması ve araştııılan konuya yönelik daha detaylı bilgi sunulması amacıyla bu çalışmada nitel yaklaşım tercih edilmiştir. Nitel yaklaşıma uygun olarak doküman analizi yönteminin uygulandığı bu araştırma, amaçlanan olgu ve durumlarla ilgili bilgi içeren yazılı kaynakların incelenmesini kapsamaktadır (Yıldırım \& Şimşek, 2013). Diğer bir ifade ile bu çalışmada sınıf öğretmenliği alanında yapılan lisansüstü tezlerin değerlendirilmesi doküman incelemesi yolu ile ele alınmıştır. Bunun için sınıf öğretmenliği alanında yapılan lisansüstü tezlere ulaşılmış, tezlerle ilgili dokümanlar elde edilmiş ve belirlenen kriterler çerçevesinde analiz edilmiştir.

\section{Çalışma Dokümanı}

Araştırmanın çalışma grubunu sınıf öğretmenliği alanında yapılan lisansüstü tezler oluşturmaktadır. Çalışmanın örneklem seçiminde amaçlı örnekleme yöntemlerinden ölçüt örnekleme tekniği kullanılmıştır. Ölçüt örnekleme tekniğinde, bir durumun belirli ölçütlere göre incelenmesi için bu ölçütlere uyan çalışma grubuyla çalışılması öngörülmektedir (Palys, 2008; Patton, 2002). Bu çerçevede araştırmada ele alınan temel ölçüt; lisansüstü tezler çerçevesinde sınıf öğretmenliği alanında hazırlanmış (izinli) olan tüm lisansüstü tezler olarak belirlenmiştir. Bir diğer ölçüt ise; 01.01.2015- 31.03.2020 yılları arasında Ulusal Tez Merkezi'nde yayınlanmış olmasıdır. Belirtilen ölçütler kapsamında; sınıf öğretmenliği alanında yüksek lisans düzeyinde toplam 644 tez, doktora düzeyinde ise 100 tez değerlendirmeye alınmıştır. 
Araştırmada verilerin toplanılması aşamasında Ulusal Tez Merkezi'ne erişilmiştir. Ulusal Tez Merkezi'nin (https://tez.yok.gov.tr/UlusalTezMerkezi/) erişim adresinden sınıf öğretmenliği alanında yapılan lisansüstü tezler elektronik ortamda toplanılmıştır. Araştırma kapsamında sınıf öğretmenliği alanında yapılan lisansüstü tezlerin incelenmesi amaciyla Ulusal Tez Merkezi sitesinde 744 tez (pdf) dosya olarak indirilerek incelenmiştir. Tezlerin analizinde araştırmanın amaçları doğrultusunda, araştırmacılar tarafından oluşturulan tez inceleme formundan yararlanılmıştır.

Tez inceleme formu oluşturulurken daha önce yapılmış çalışmalardaki tez inceleme formları dikkate alınmıştır. Araştırma kapsamı dâhilinde mevcut tezlerle ilgili incelenen başlıklar çalışmaya dâhil edilmiş bu başlıklara ek olarak çalışmanın alt problemlerinde yer alan başlıklarda da eklenmiştir. Süreç içinde alanda uzman olan iki kişinin görüşü alınarak formların son şekilleri oluşturulmuştur. Formun son halinde yer alan kriterler; tezlerin düzeyleri (yüksek lisans / doktora), araştırmacıların cinsiyeti, tezlerin hazırlandıkları üniversite, bilim dalı, danışman unvanları, hazırlandığı yıl, uygulandığı sınıf düzeyi, kullanılan yöntem, uygulandığı örneklem/çalışma grupları, kullanılan veri toplama araçları ve uygulanan analiz türleri şeklindedir.

\section{Verilerin Analizi}

Nitel araştırma deseni benimsenen bu çalışmada verilerin analizinde, doküman analizi kullanılmıştır. Fraenkel ve Wallen (2006), doküman incelemesi için sekiz aşama belirlemiştir. Bu aşamalar sırasıyla;

- İçerik analizinin yapılma amacının belirlenmesi,

- Neyin analiz edileceğine karar verilen analiz birimlerinin belirlenmesi,

- Araştırma amacina uygun olarak analiz edilecek verilerin saptanması,

- Elde edilen veriler ile amaçlar arasındaki ilişkiyi ifade eden mantıksal bir yapının oluşturulması,

- Araştırmacının örneklem planını geliştirmesi ve kodlaması,

- Kategorilerin belirlenmesi aşamalarının izlenmesi ve verilerin analiz için hazırlanması,

- Amaçlı örneklem kullanılması,

- Çalışmanın dokümanlarının başka bir uzman tarafından incelendiğinde de aynı sonuçlar ortaya çıkacak niteliğe sahip olması şeklinde belirtilmiştir.

$\mathrm{Bu}$ araştırmada bahsi geçen aşamalara dikkate edilerek verilerin analizi gerçekleştirilmiştir. İncelenen sınıf öğretmenliği alanına ait tezlere dayalı olarak belirlenen ilgili temalar incelenmiştir. Daha sonra ele alınan temalar başka bir uzman tarafından da değerlendirilmiştir. Araştırmada bir eş gözlemciyle çalışılmıştır. Araştırmacılar arasındaki görüş birliğini tespit etmek için Miles ve Huberman (1994)'ın belirlediği güvenirlik formülü

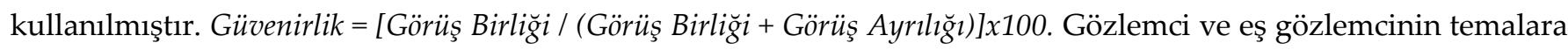
yaptıkları kodlamaların tutarlılığı \%95 olarak hesaplanmıştır. Bunun yanında her bir temaya ait elde edinilen bulgular frekans (f) ve yüzde (\%) olarak tablolar halinde sunulmuştur.

\section{BULGULAR}

Sınıf öğretmenliği bilim dalı ile ilgili yapılan lisansüstü eğitim tezlerinin düzeylerine göre incelenmesinden elde edilen frekans ve yüzdelik değerleri Tablo 1'de belirtilmiştir.

Tablo 1. İncelenen Lisansüstü Tezlerin Düzeylerine Göre Dağılımı

\begin{tabular}{ccccc}
\hline \multicolumn{3}{c}{ Lisansüstü Tez Dağılımı } \\
\hline & Yüksek Lisans & & & Doktora \\
\hline $\mathrm{f}$ & & $\%$ & $\mathrm{f}$ & $\%$ \\
\hline 644 & & 86.6 & 100 & 13.4 \\
\hline
\end{tabular}

Tablo 1'de ele alındığı gibi lisansüstü çerçevede sınıf öğretmenliği bilim dalında yüksek lisans ve doktorada hazırlanmış toplam 744 tezin olduğu görülmüştür. Hazırlanan tezlerin \%86,6'lık bölümünü yüksek lisans, \%13,4'lük 
kısmını ise doktora tezi oluşturmuştur. Belirtilen yüzdelikler doğrultusunda lisansüstü tezlerin büyük oranını yüksek lisans tezlerinin oluşturduğu görülmüştür. Tezlerin araştırmacı cinsiyetlerine göre dağılımlarının yer aldığı frekans ve yüzdelik değerleri ise Tablo 2' de sunulmuştur.

Tablo 2. İncelenen Tezlerin Araştırmacı Cinsiyetlerine Göre Dağılımı

\begin{tabular}{ccccc}
\hline \multirow{2}{*}{ Araştırmacı Cinsiyet Dağılımı } & \multicolumn{2}{c}{ Yüksek Lisans } & \multicolumn{2}{c}{ Doktora } \\
\cline { 2 - 5 } & $\mathrm{f}$ & $\%$ & $\mathrm{f}$ & 48 \\
\hline Kadın & 362 & 56.2 & 48 & 52 \\
Erkek & 282 & 43.8 & 52 \\
\hline
\end{tabular}

Tablo 2'de belirtildiği gibi sınıf öğretmenliği bilim dalında yapılan yüksek lisans tezlerinin \%56.2'si kadınlar, \%43.8'i erkekler tarafından hazırlanmıştır. Doktora boyutunda ise tezlerin \%52'si erkek ve \%48'inin kadınlar tarafından yapıldığı görülmüştür. Cinsiyet dağılımına göre değerlendirildiğinde; yüksek lisans tezlerinin hazırlanmasında kadınların, doktora tezlerinin hazırlanmasında ise erkeklerin yoğunluk oluşturduğu belirtilmiştir. İncelenen tezlerin hazırlandıkları üniversitelere göre dağılımları Tablo 3'te gösterilmiştir.

Tablo 3. İncelenen Tezlerin Hazırlandığı Üniversitelere Göre Dağılımı

\begin{tabular}{|c|c|c|c|c|}
\hline \multirow{2}{*}{ İncelenen Tezlerin Hazırlandığı Üniversiteler } & \multicolumn{2}{|c|}{ Yüksek Lisans } & \multicolumn{2}{|c|}{ Doktora } \\
\hline & $\mathrm{f}$ & $\%$ & f & $\%$ \\
\hline Abant İzzet Baysal Üniversitesi & 11 & 1.7 & - & - \\
\hline Adnan Menderes Üniversitesi & 14 & 2.2 & - & - \\
\hline Afyon Kocatepe Üniversitesi & 10 & 1.6 & - & - \\
\hline Ağrı İbrahim Çeçen Üniversitesi & 11 & 1.7 & - & - \\
\hline Ahi Evran Üniversitesi & 8 & 1.2 & - & - \\
\hline Akdeniz Üniversitesi & 1 & 0.2 & - & - \\
\hline Aksaray Üniversitesi & 5 & 0.8 & - & - \\
\hline Amasya Üniversitesi & 35 & 5.4 & 3 & 3 \\
\hline Anadolu Üniversitesi & 7 & 1.1 & 13 & 13 \\
\hline Atatürk Üniversitesi & 23 & 3.6 & 4 & 4 \\
\hline Bartın Üniversitesi & 6 & 0.9 & - & - \\
\hline Bayburt Üniversitesi & 12 & 1.9 & - & - \\
\hline Bursa Uludağ Üniversitesi & 7 & 1.1 & 1 & 1 \\
\hline Çanakkale 18 Mart Üniversitesi & 44 & 6.9 & - & - \\
\hline Dicle Üniversitesi & 2 & 0.3 & - & - \\
\hline Dokuz Eylül Üniversitesi & 14 & 2.2 & 1 & 1 \\
\hline Dumlupınar Üniversitesi & 9 & 1.4 & 13 & 13 \\
\hline Düzce Üniversitesi & 3 & 0.5 & - & - \\
\hline Ege Üniversitesi & 7 & 1.1 & - & - \\
\hline Erzincan Üniversitesi & 15 & 2.3 & - & - \\
\hline Eskişehir Osmangazi Üniversitesi & 12 & 1.9 & - & - \\
\hline Firat Üniversitesi & 39 & 6.1 & - & - \\
\hline Gazi Üniversitesi & 16 & 2.5 & 17 & 17 \\
\hline Gaziantep Üniversitesi & 14 & 2.2 & - & - \\
\hline Gaziosmanpaşa Üniversitesi & 25 & 3.9 & - & - \\
\hline Giresun Üniversitesi & 16 & 2.5 & - & - \\
\hline Hacettepe Üniversitesi & 3 & 0.5 & - & - \\
\hline Hatay Mustafa Kemal Üniversitesi & 3 & 0.5 & - & - \\
\hline İnönü Üniversitesi & 11 & 1.7 & 3 & 3 \\
\hline İstanbul Üniversitesi & 1 & 0.2 & 2 & 2 \\
\hline İstanbul Aydın Üniversitesi & 16 & 2.5 & - & - \\
\hline Kastamonu Üniversitesi & 12 & 1.9 & - & - \\
\hline Karadeniz Teknik Üniversitesi & 12 & 1.9 & - & - \\
\hline Kırıkkale Üniversitesi & 1 & 0.2 & - & - \\
\hline
\end{tabular}




\begin{tabular}{|c|c|c|c|c|}
\hline Kocaeli Üniversitesi & 6 & 0.9 & - & - \\
\hline Manisa Celal Bayar Üniversitesi & 8 & 1.2 & - & - \\
\hline Marmara Üniversitesi & 10 & 1.6 & 14 & 14 \\
\hline Mehmet Akif Ersoy Üniversitesi & 27 & 4.2 & 5 & 5 \\
\hline Mersin Üniversitesi & 11 & 1.7 & - & - \\
\hline Muğla Sıtk1 Koçman Üniversitesi & 4 & 0.6 & - & - \\
\hline Necmettin Erbakan Üniversitesi & 60 & 9.4 & 10 & 10 \\
\hline Niğde Ömer Halisdemir Üniversitesi & 9 & 1.4 & - & - \\
\hline Ondokuz Mayıs Üniversitesi & 6 & 0.9 & 7 & 7 \\
\hline Ordu Üniversitesi & 7 & 1.1 & - & - \\
\hline Pamukkale Üniversitesi & 15 & 2.3 & 7 & 7 \\
\hline Sakarya Üniversitesi & 15 & 2.3 & - & - \\
\hline Trakya Üniversitesi & 5 & 0.8 & - & - \\
\hline Trabzon Üniversitesi & 2 & 0.3 & - & - \\
\hline Uşak Üniversitesi & 26 & 4 & - & - \\
\hline Yıldız Teknik Üniversitesi & 1 & 0.2 & - & - \\
\hline Yozgat Bozok Üniversitesi & 3 & 0.5 & - & - \\
\hline
\end{tabular}

Tablo 3'te gösterildiği gibi lisansüstü tezlerin üniversitelere göre dağılımı incelendiğinde; yüksek lisans tezlerinin \%9,4'lük oranın Necmettin Erbakan Üniversitesi, \%6.9’luk kısmının Çanakkale 18 Mart Üniversitesi ve \% 6.1'lik kısmının Fırat Üniversitesi tarafından gerçekleştirildiği dikkati çekmiştir. Doktora tezlerinin hazırlanmasındaki dağılım incelendiğinde ise; \%17'lik kısmın Gazi Üniversitesi, \%14'lük oranın Marmara Üniversitesi, \%13'lük dilimin Anadolu Üniversitesi ve Dumlupınar Üniversitesi tarafından gerçekleştirildiği görülmektedir. Belirtilen yüzdelikler doğrultusunda; Necmettin Erbakan Üniversitesi'nin yüksek lisans tezlerinin hazırlanmasında diğer üniversitelere göre daha yüksek bir orana sahip olduğu, benzer nitelikte doktora tezlerinin hazırlanmasında Gazi Üniversitesi'nin yine diğer üniversitelere göre daha yüksek bir dağılım gösterdiği görülmüştür. Tezlerin bilim dallarına göre incelenmesinden elde edilen frekans ve yüzdelik değerleri Tablo 4 'te verilmiştir.

Tablo 4. İncelenen Tezlerin Bilim Dallarına Göre Dağılımı

\begin{tabular}{|c|c|c|c|c|}
\hline \multirow{2}{*}{ Tezlerde Çalışılan Bilim Dalları } & \multicolumn{2}{|c|}{ Yüksek Lisans } & \multicolumn{2}{|c|}{ Doktora } \\
\hline & $\mathrm{f}$ & $\%$ & $\mathrm{f}$ & $\%$ \\
\hline Beden Eğitimi ve Oyun & 8 & 1.32 & 1 & 1 \\
\hline Fen Bilgisi Eğitimi & 85 & 13.19 & 17 & 17 \\
\hline Hayat Bilgisi Eğitimi & 21 & 3.26 & 6 & 6 \\
\hline İlk Okuma Yazma ve Türkçe Eğitimi & 131 & 20.34 & 19 & 19 \\
\hline Matematik Eğitimi & 64 & 9.94 & 15 & 15 \\
\hline Müzik Eğitimi & 7 & 1.08 & 1 & 1 \\
\hline Okul Öncesi Eğitimi & 15 & 2.33 & - & - \\
\hline Resim/Resim- İş Eğitimi & 5 & 0.77 & - & - \\
\hline Sosyal Bilgiler Eğitimi & 32 & 4.97 & 17 & 17 \\
\hline $\begin{array}{l}\text { Diğer (Eğitim yönetimi, program } \\
\text { geliştirme, rehberlik psikolojik } \\
\text { danışmanlık, vb.) }\end{array}$ & 276 & 42.8 & 24 & 24 \\
\hline
\end{tabular}

Tablo 4'te belirtildiği gibi incelenen yüksek lisans tezleri bilim dallarına göre değerlendirildiğinde bunların \%42,8'ini “Diğer" (Eğitim yönetimi, program geliştirme, rehberlik psikolojik danışmanlık, vb.), \% 20.34'ünü “ïlk Okuma Yazma ve Türkçe Eğitimi" ve \% 13.19'unu "Fen Bilgisi Eğitimi" oluşturmuştur. Hazırlanan doktora tezlerinde ise bu durum incelendiğinde; tezlerin \%24'ünü "Diğer" (Eğitim yönetimi, program geliştirme, rehberlik psikolojik danışmanlık, vb.) \%19'unu "illk Okuma Yazma ve Türkçe Eğitimi", \%17'sini ise "Fen Bilgisi" ve "Sosyal Bilgiler Eğitimi" şeklinde benzer bir sıra izlediği yönünde görülmüştür. Bu bağlamda yüksek lisans ve doktora tezlerinin çoğunluğunun “Diğer” (Eğitim yönetimi, program geliştirme, rehberlik psikolojik danışmanlık, vb.) bilim

| Manisa Celal Bayar University Journal of The Faculty of Education, 2021, Vol. 9, No. 2 | 
dalında yoğunlaştı̆̆ı şeklinde ifade edilebilir. Tezlerin danışman unvanlarına göre incelenmesinden elde edilen frekans ve yüzdelik değerleri Tablo 5 'te gösterilmiştir.

Tablo 5. Tezlerin Danışman Unvanlarına Göre Dağılımı

\begin{tabular}{ccccc}
\hline \multirow{2}{*}{$\begin{array}{c}\text { Hazırlanan Tezlerin Danışmanlarının } \\
\text { Unvanları }\end{array}$} & \multicolumn{2}{c}{ Yüksek Lisans } & \multicolumn{2}{c}{ Doktora } \\
\cline { 2 - 5 } & $\mathrm{f}$ & $\%$ & $\mathrm{f}$ & \% \\
\hline Dr. & 2 & 0.31 & 13 & 13 \\
Dr. Öğretim Üyesi & 223 & 34.6 & 39 & 39 \\
Doç. Dr. & 237 & 36.8 & 48 & 48 \\
Prof. Dr. & 182 & 28.29 & & 13 \\
\hline
\end{tabular}

Tablo 5'te gösterildiği gibi hazırlanan tezler danışman unvanları açısından ele alındığında; yüksek lisans tezlerinin \%36,8'ini “Doç. Dr." unvanına sahip olan bilim insanları, doktora tezlerinin ise \%48'ini "Prof. Dr." unvanına sahip bilim insanları oluşturmuştur. Belirtilen yüzdelik değerler doğrultusunda tezlerin hazırlanmasında “Doç. Dr." ve "Prof. Dr." unvanlarının yoğunluk kazandığı görülmüştür. Tezlerin hazırlandıkları yıllara göre incelenmesinden elde edilen frekans ve yüzdelik değerler ise Tablo 6' da yer almaktadır.

Tablo 6. İncelenen Tezlerin Hazırlandıkları Yıllara Göre Dağılımı

\begin{tabular}{ccccc}
\hline \multirow{2}{*}{ Tezlerin Hazırlandikları Yillar } & \multicolumn{2}{c}{ Yüksek Lisans } & \multicolumn{2}{c}{ Doktora } \\
\cline { 2 - 5 } & $\mathrm{f}$ & $\%$ & $\mathrm{f}$ & 22 \\
\hline 2015 & 86 & 13.4 & 16 & 22 \\
2016 & 70 & 10.9 & 17 & 16 \\
2017 & 71 & 11 & 21 & 17 \\
2018 & 92 & 14.3 & 23 & 21 \\
2019 & 310 & 48.1 & 1 & 23 \\
2020 & 15 & 2.3 & 1 \\
\hline
\end{tabular}

Tablo 6 incelendiğinde; tezlerin hazırlandıkları yıllar açısından son beş yıl değerlendirildiğinde 2019 yılında diğer yıllara göre daha yoğun bir oranda tezlerin oluşturulduğu görülmüştür. Belirtilen bu yılda yüksek lisans düzeyinde hazırlanan tezler $\% 48,1$, doktora tezleri ise $\% 23$ 'lük bir kısmı oluşturmuştur. Yüksek lisans düzeyinde 2019 yılını, \%14,3'lük bir oranla 2018 yılı takip etmiştir. Doktora düzeyinde ise 2019 yılını, \%22'lik dilimle 2015 yılı izlemiştir. Tezlerin uygulama yapılan sınıflara göre dağılımının yer aldığı frekans ve yüzdelik değerleri Tablo 7'de belirtilmiştir.

Tablo 7. İncelenen Tezlerin Uygulama Yapılan Sınıflara Göre Dağılımı

\begin{tabular}{ccccc}
\hline \multirow{2}{*}{ Tezlerde Uygulama Yapılan Sinıflar } & \multicolumn{2}{c}{ Yüksek Lisans } & \multicolumn{2}{c}{ Doktora } \\
\cline { 2 - 5 } & $\mathrm{f}$ & $\%$ & $\mathrm{f}$ & 4 \\
\hline 1. Sınıf & 16 & 2.5 & 4 & 4 \\
2. Sinıf & 16 & 2.5 & 9 & 5 \\
3. Sınıf & 29 & 4.5 & 55 & 55 \\
4. Sınıf & 145 & 22.5 & 28 & 28 \\
Diğger (okul öncesi, ortaokul, lise, & & 68 & \\
öğretmen adayları, özel eğitim & 438 & & \\
öğrencileri) & & & \\
\hline
\end{tabular}

Tablo 7'de gösterildiği gibi yüksek lisans düzeyinde hazırlanan tezlerin \%68'lik kısmının "Diğer" (okul öncesi, ortaokul, lise, öğretmen adayları, özel eğitim öğrencileri) uygulama sınıfları boyutunda yoğunluk kazandığı, bu oranı "4. Sınıf" düzeyinde yapılan çalışmaların \%22,5'lik bir kısımla izlediği görülmüştür. Doktora düzeyinde yapılan tezlerde ise, " 4 . Sınıf" düzeyinde gerçekleştirilen tezlerin \%55'lik bir dilime sahip olduğu, bu oranı \%28'lik bir kısımla "Diğer" uygulama sınıflarının oluşturduğu belirlenmiştir. Tezlerin kullanılan araştırma yöntemlerine göre incelenmesinden elde edilen frekans ve yüzdelik değerlerine ise Tablo 8 'de yer verilmiştir. 
Tablo 8. İncelenen Tezlerde Kullanılan Araştırma Yöntemleri

\begin{tabular}{ccccc}
\hline Tezlerde Kullanılan Araştırma & \multicolumn{2}{c}{ Yüksek Lisans } & \multicolumn{2}{c}{ Doktora } \\
\cline { 2 - 5 } Yöntemleri & $\mathrm{f}$ & $\%$ & $\mathrm{f}$ & 29 \\
\hline Nitel & 219 & 34 & 16 & 29 \\
Nicel & 350 & 54.4 & 55 & 16 \\
Karma & 75 & 11.6 & 55 \\
\hline
\end{tabular}

Tablo 8'de belirtildiği gibi tezlerde kullanılan yöntemler açısından incelendiğinde; yüksek lisans düzeyinde araştırmacılar tarafından daha çok nicel boyutun yöntem olarak tercih edildiği \%54,4'lük bir oranla ifade edilmiştir. $\mathrm{Bu}$ oranı \%34'lük bir kısımla nitel yöntem takip etmiştir. Yöntem boyutunda doktora tezleri açısından değerlendirildiğinde araştırmacılar çalışmalarında daha çok karma yöntemi tercih etmiş (\%55) bu sırayı ise nitel yöntem (\%29) izlemiştir. Belirtilen yüzdelik değerlerle ifade edildiği gibi yüksek lisans tezlerinde daha çok niceliksel değerler ön planda tutulurken, doktora düzeyinde hazırlanan tezlerde nicelik ve niteliğin bir arada değerlendirildiği karma yöntem tercih edilmektedir. Tezlerin örneklem/çalışma gruplarına göre dağılımlarının yer aldı̆̆ı frekans ve yüzdelik değerler Tablo 9'de gösterilmiştir.

Tablo 9. İncelenen Tezlerde Yer Alan Örneklem/ Çalışma Grupları

\begin{tabular}{ccccc}
\hline Tezlerde Yer Alan Örneklem/ Çalışma & \multicolumn{2}{c}{ Yüksek Lisans } & \multicolumn{2}{c}{ Doktora } \\
\cline { 2 - 5 } Grupları & $\mathrm{f}$ & $\%$ & $\mathrm{f}$ & - \\
\hline Okul Öncesi & 5 & 0.7 & 73 & 73 \\
İlkokul & 257 & 40 & 3 & 3 \\
Ortaokul & 21 & 3.2 & - & - \\
Lise & 5 & 0.7 & 7 & 7 \\
Öğretmen Adayı & 63 & 9.7 & 13 & 13 \\
Öğretmen & 237 & 37 & 4 & 4 \\
Diğer (Okul yöneticileri, veliler, doküman & 56 & 8.7 & \\
incelemesi, karşılaştırmalı eğitim) & & & \\
\hline
\end{tabular}

Tablo 9' da gösterildiği gibi tezlerde yer alan çalışma grupları yüksek lisans düzeyinde incelendiğinde; \%40’lık bir kısımla "ilkokul öğrencilerinin” oluşturduğu, bu oranı \%37'lik bir dilimle “öğretmen” çalışma grubunun izlediği görülmüştür. Hazırlanan tezlerin çalışma gruplarının oranları "öğretmen adayı" ve "diğer" (Okul yöneticileri, veliler, doküman incelemesi, karşılaştırmalı eğitim) çalışma grupları boyutuyla devam etmiştir. Doktora düzeyinde hazırlanan tezlerdeki çalışma gruplarına bakıldığında yine yüksek lisans düzeyine benzer bir yapı göstererek en çok “ilkokul öğrencileri” (\%73) ile çalışıldı̆̆ı̆, akabinde ise “öğretmen” (\%13) çalışma grubunun takip ettiği belirlenmiştir. Yüksek lisans tezlerinin en az okul öncesi ve lise grupları ile yapıldığı doktora tezlerinde ise en az ortaokul grupları ile gerçekleştirildiği dikkat çekmiştir. Doktora tezlerinde okul öncesi ve lise gruplarına yer verilmediği diğer bir dikkat çeken nokta olmuştur. Bu durum sınıf öğretmenliği ana bilim dalıyla yapılan tezlerin araştırmacılar tarafından daha çok alanda çalışılmak istendiği, sınıf eğitimi düzeyinde yani ilkokul öğrencileri ile birlikte gerçekleştirilmeye çalışıldığı yönünde yorumlanmıştır. Tezlerin veri toplama araçlarına göre incelenmesinden elde edilen frekans ve yüzdelik değerleri ise Tablo 10'da verilmiştir.

Tablo 10. İncelenen Tezlerde Kullanılan Veri Toplama Araçları

\begin{tabular}{|c|c|c|c|c|}
\hline \multirow{2}{*}{$\begin{array}{l}\text { Tezlerde Kullanılan Veri Toplama } \\
\text { Araçları }\end{array}$} & \multicolumn{2}{|c|}{ Yüksek Lisans } & \multicolumn{2}{|c|}{ Doktora } \\
\hline & $\mathrm{f}$ & $\%$ & $\mathrm{f}$ & $\%$ \\
\hline Anket & 104 & 9.3 & 14 & 4.0 \\
\hline Test & 113 & 10.1 & 43 & 12.4 \\
\hline Ölçek & 308 & 27.6 & 60 & 17.2 \\
\hline Gözlem & 41 & 3.7 & 46 & 13.2 \\
\hline Görüşme & 215 & 19.3 & 72 & 20.7 \\
\hline Doküman & 125 & 11.2 & 40 & 11.5 \\
\hline
\end{tabular}

| Manisa Celal Bayar University Journal of The Faculty of Education, 2021, Vol. 9, No. 2 | 
Tablo 10'da belirtildiği gibi hazırlanan tezlerde kullanılan veri toplama araçları yüksek lisans düzeyinde ele alındığında; en çok tercih edilen veri toplama araçlarının, ölçek $(\% 27,6)$, görüşme $(\% 19,3)$, diğer (\%17) ve doküman şeklinde olduğu görülmüştür. Doktora düzeyinde hazırlanan tezlerde ise en çok tercih edilen veri toplama araçları ise; görüşme (\%20,7), ölçek (\%17,2), gözlem (\%13.2) ve test (\%12.4) olarak belirlenmiştir. İlgili tablo üzerinde ayrıca açıklama getirilecek bir husus da şudur: Hazırlanan hem yüksek lisans hem de doktora tezlerinde birden fazla veri toplama aracı kullanılmıştır. Bu durum frekans ve yüzdelik değerlerine de aktarılmıştır. Tezlerde uygulanan analizlerin yöntemlerine göre dağılımlarının incelendiği frekans ve yüzdelik değerleri ise Tablo 11'de gösterilmiştir.

Tablo 11. İncelenen Tezlerde Uygulanan Analiz Yöntemleri

\begin{tabular}{|c|c|c|c|c|c|}
\hline & Uygulanan Analiz Yöntemleri & & & & \\
\hline \multirow{20}{*}{ 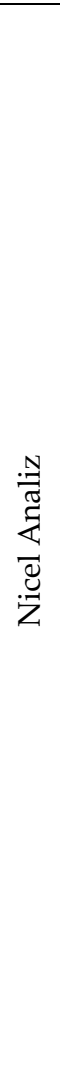 } & Betimsel & $\mathrm{f}$ & $\%$ & $\mathrm{f}$ & $\%$ \\
\hline & Aritmetik Ortalama & 193 & 9.2 & 34 & 8.6 \\
\hline & Frekans, Yüzde & 300 & 14.3 & 32 & 8.1 \\
\hline & Standart Sapma & 165 & 7.9 & 29 & 7.3 \\
\hline & Vardamsal & & & & \\
\hline & Faktör Analizi & 62 & 2.9 & 13 & 3.3 \\
\hline & Güvenirlik Analizi & 113 & 5.3 & 12 & 3 \\
\hline & T- testi & 281 & 13.3 & 49 & 12.4 \\
\hline & Anova (Varyans Analizi) & 200 & 9.5 & 29 & 7.3 \\
\hline & Kovaryans Analizi (Ancova) & 16 & 0.8 & 12 & 3 \\
\hline & Wilcoxon Testi & 34 & 1.6 & 19 & 4.8 \\
\hline & Mancova Testi & 2 & 0.1 & 1 & 0.3 \\
\hline & Kruskall Wallis & 95 & 4.5 & 9 & 2.3 \\
\hline & Regresyon & 36 & 1.7 & 6 & 1.5 \\
\hline & Ki Kare & 25 & 1.2 & 6 & 1.5 \\
\hline & Korelasyon & 123 & 5.9 & 13 & 3.3 \\
\hline & Manova Testi & 2 & 0.1 & 3 & 0.8 \\
\hline & Diskriminant Analizi & - & - & 1 & 0.3 \\
\hline & Mann Whitney U Testi & 132 & 6.3 & 27 & 6.8 \\
\hline & Yapısal Eşitlik (Yol) Testi & - & - & 1 & 0.3 \\
\hline \multirow{6}{*}{ 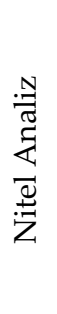 } & Betimsel Analiz & 135 & 6.4 & 38 & 9.6 \\
\hline & İçerik Analizi & 185 & 8.8 & 58 & 14.7 \\
\hline & Sistem Analitik Analiz & - & - & 2 & 0.5 \\
\hline & Söylem Analizi & 1 & 0.05 & 1 & 0.3 \\
\hline & Sürekli Karşılaştırmalı Analiz & 2 & 0.1 & - & - \\
\hline & Meta Analiz & 1 & 0.05 & - & - \\
\hline
\end{tabular}

Tablo 11' de gösterildiği gibi hazırlanan yüksek tezlerinde uygulanan analiz yöntemleri ele alındığında; nicel yöntem bakımından betimsel olarak tezlerde en çok frekans ve yüzdelik $(\% 14,3)$ değerlerinin sunulduğu görülmüştür. Yine nicel yöntemde vardamsal açıdan kullanılan analizler incelendiğinde; en çok t-testi (\%13,3), Anova $(\% 9,5)$, Mann Whitney u $(\% 6,3)$, korelasyon $(\% 5,9)$ ve güvenirlik analizinin $(\% 5,3)$ tercih edildiği belirlenmiştir. Uygulanan analizler nitel yöntem açısından değerlendirildiğinde; içerik analizinin $(\% 8,8)$ ve betimsel analizin $(\% 6,4)$ en çok uygulandığı, bu oranı sürekli karşılaştırmalı analiz $(\% 0,1)$, söylem analizi $(\% 0.05)$ ve meta analizin (\%0.05) izlediği dikkat çekmiştir. Doktora düzeyinde hazırlanan tezlerde kullanılan analiz yöntemlerine bakıldığında; nicel yöntem açısından betimsel olarak tezlerde aritmetik ortalama $(\% 8,6)$ değerinin en çok tercih edildiği göze çarpmıştır. Yine nicel yöntemde vardamsal açıdan kullanılan analizler incelendiğinde; en çok t-testi 
$(\% 12,4)$, Anova $(\% 7,3)$, Mann Whitney u $(\% 6,8)$ ve Wilcoxon testi $(\% 4,8)$ tercih edilmiştir. Nitel boyutta en çok uygulanan analizlerin; içerik analizi $(\% 14,7)$ ve betimsel analiz $(\% 9,6)$ olduğu, bu analizlerin yanında sistem analitik analiz $(\% 0,5)$ ve söylem analizinin $(\% 0.3)$ de tercih edildiği belirlenmiştir. İlgili tablo üzerinde açıklama getirilecek bir nokta ise şudur: Hazırlanan hem yüksek lisans hem de doktora tezlerinde birden fazla analiz yöntemi kullanılmıştır. Bu durum frekans ve yüzdelik değerlerine de yansıtılmıştır.

\section{SONUÇ ve TARTIŞMA}

Sınıf öğretmenliği alanında yapılan tezlerin lisansüstü boyutta incelenmesinin çalışıldığı bu araştırmada şu sonuçlara ulaşılmıştır: Toplam tezlerin \%86,6'lık bölümünü yüksek lisans, \%13,4'lük kısmını ise doktora tezi oluşturmaktadır. Buna göre lisansüstü tezlerin büyük oranını yüksek lisans tezlerinin oluşturduğu görülmektedir. Elde edilen bu sonuç; Şahin, Calp, Bulut ve Kuşdemir' in (2013) çalışmasıyla benzerlik taşımaktadır. İlgili araştırmada 2005-2010 yılları arasında incelenen tezlerde de yüksek lisans tezlerinin doktora tezlerine göre daha fazla bulunduğu sonucuna ulaşılmıştır.

Tezlerin üniversitelere göre dağılımı incelendiğinde; 51 üniversitede yüksek lisans tezinin, 14 üniversitede doktora tezinin yapıldı̆̆ı görülmektedir. Üniversiteler bazında Necmettin Erbakan Üniversitesi'nin yüksek lisans tezlerinin hazırlanmasında, Gazi Üniversitesi'nin de doktora tezlerinin hazırlanmasında diğer üniversitelere göre daha yüksek bir dağılım gösterdiği sonucu elde edilmiştir. İncelenen tezlerin bilim dallarına göre verilerine bakıldığında hem yüksek lisans hem de doktora tezlerinde "eğitim yönetimi, program geliştirme, rehberlik psikolojik danışmanlık, vb." bilim dallarında daha fazla çalışmanın yapıldı̆̆ı bulgusuna ulaşılmıştır. Bu sonuç sınıf öğretmenliği doçentlik bilim alanlarına göre bakıldığında, tezlerin temel bilim dallarından daha farklı bilim dallarında hazırlandığı durumunu göstermiştir. Araştırmada elde edinilen bir diğer bulgu ise yüksek lisans tezlerinin hazırlanmasında "Doç. Dr." unvanlı öğretim üyelerinin doktora tezlerinin hazırlanmasında ise "Prof. Dr." unvanlı öğretim üyelerinin danışmanlık yaptığı görülmüştür. Bu durum, lisansüstü eğitimde programlara göre görevlendirmede akademik unvanların da dikkate alındığını göstermektedir. Diğer bir ifadeyle, doktora tezlerinin hazırlanmasında daha deneyimli unvanların tercih edildiği görülmektedir.

Çalışmada incelenen tezlerin çalışma gruplarına bakıldığında "okul öncesi, ortaokul, lise, öğretmen adayları, özel eğitim öğrencileri” ile daha fazla çalışmanın gerçekleştiği bulgusu elde edilmiştir. Bu sonuç, yapılan tezlerde uygulama yapılan sınıflar boyutuyla da benzerlik taşımaktadır. Sınıf düzeyiyle ilgili olarak sınıf eğitimi için önemli olan ilkokul 1., 2., 3. ve 4. sınıf düzeyinde çalışmanın daha az yapıldı̆̆ı sonucunu beraberinde getirmiştir. İncelenen tezlerde kullanılan yöntemler açısından bakıldığında yüksek lisans çalışmalarının çoğunun nicel araştırma yöntemi ile yapıldığıı, doktora tezlerinin ise daha çok karma yöntemlerle hazırlandığı görülmüştür. Elde edilen bu sonuç Küçükoğlu ve Ozan’ ın (2013) araştırmasıyla da benzerlik göstermiştir. Küçükoğlu ve Ozan’ ın (2013) çalışmasında da yüksek lisans tezlerinin çoğunluğunda $(\% 67,4)$ nicel yöntem kullanıldı̆̆ı, doktora tezlerinde ise nicel $(\% 38,2)$, nitel $(\% 34,5)$ ve karma $(\% 30,9)$ yöntemler arasında dengeli bir dağılımın olduğu sonucuna ulaşılmıştır.

İncelenen tezlerde kullanılan veri toplama araçlarına göre yüksek lisans tezlerinde ölçeklerin daha çok tercih edildiği, doktora tezlerinde ise görüşme tekniğinin daha fazla kullanıldığı bulgusu elde edilmiştir. Bu sonuç, Küçükoğlu ve Ozan'ın (2013) çalışmasıyla örtüşmektedir. Belirtilen araştırmada da yüksek lisans ve doktora tezlerinde veri toplama araçlarına göre en çok anket ya da ölçeklerin kullanıldı̆̆ı ifade edilmiştir. Yine elde edilen bir diğer sonuç da uygulanan analiz yöntemleri ile ilgilidir. Yüksek lisans tezlerinde uygulanan analiz yöntemlerinde nicel boyutta en çok frekans ve yüzdelik değerleri, t-testi, Anova, Mann Whitney u, korelasyon ve güvenirlik analizinin tercih edildiği, nitel yöntem açısından ise içerik analizinin kullanıldığı görülmektedir. Doktora düzeyinde ise; nicel yöntem açısından aritmetik ortalama, t-testi, Anova, Mann Whitney u ve Wilcoxon testinin, nitel boyutta ise içerik analizinin tercih edildiği sonucuna ulaşılmıştır. Araştırma sonucu Küçükoğlu ve Ozan'ın (2013) çalışmasıyla benzerlik göstermiş, ilgili çalışmada da veri analiz tekniklerine göre tezlerde en çok sırasıyla ortalama/standart sapma değerleri, t-testi, frekans/yüzde değerleri ve ANOVA uygulanmış, nitel analiz tekniklerinden ise en çok betimsel analiz tekniği kullanılmıştır. Yine çalışma, Özenç ve Özenç' in (2013)

| Manisa Celal Bayar University Journal of The Faculty of Education, 2021, Vol. 9, No. 2 | 
araştırmasıyla örtüşmüş, ilgili çalışmada da en fazla kullanılan istatistik tekniklerinin frekans, yüzde, aritmetik ortalama, standart sapma, t testi ve tek yönlü varyans analizinin olduğu dolayısıyla betimsel istatistik ve parametrik tekniklerin daha fazla kullanıldığı sonucu elde edilmiştir. Edinilen bulgular sonucunda tezlerde; yüksek lisans düzeyinde genel olarak temel istatistiki ölçümlerin yapıldığı, doktora boyutunda ise daha detaylı ölçüm ve değerlendirmeler yapıldığı yorumu getirilmiştir.

Araştırmanın sonuçlarına yönelik olarak aşağıdaki öneriler eklenebilir: Üniversiteler bazında incelendiğinde yüksek lisans tezlerinin doktora tezlerine oranla daha çok yapıldı̆̆ı dikkati çekmektedir. Bu anlamda sınıf öğretmenliği alanında doktora tezlerinin arttırılması için daha çok doktora programları açılabilir. Sınıf öğretmenliği anabilim dalında doçentlik bilim dallarına göre çalışmaların artırılması sağlanabilir. Yüksek lisans tez çalışmalarına bakıldığında daha çok nicel tezlerin yürütüldüğ̈̈, doktora programında ise karma yöntemle yapılan tezlerin yoğunlukta olduğu görülmektedir. Bu sebeple yüksek lisans tez çalışmalarında nitel ve karma yöntemli araştırmaların yürütülmesine ağırlık verilebilir. Yapılan tezlerin analizlerinde betimsel istatistik yöntemleri ve temel istatistiksel yöntemler kullanılmıştır. Bu anlamda yapılacak tezlerde nicel analiz yöntemleri bakımından daha ileri istatistiki yöntemler kullanılabilir. İncelenen tezlerde nitel analiz yöntemi açısından içerik analiz yönteminin ağırlıklı kullanıldığı görülmektedir. Buna göre nitel analiz yöntemi açısından ise farklı desenler uygulanabilir (Söylem analizi, etnografik, fenemonoloji, vs.). 


\section{KAYNAKÇA}

Bıkmaz, F., Aksoy, E., Tatar, Ö., ve Atak-Altınyüzük, C. (2013). Eğitim programları ve öğretim alanında yapılan doktora tezlerine ait içerik çözümlemesi (1974-2009). Eğitim ve Bilim, 38(68) 288-303.

Bryman, A. (2006). Quantity and quality in social research. London: Routledge.

Creswell, J. W. (2008). Educational research planning, conducting and evaluating quantitative and qualitative research. New York: International Pearson Merril Prentice Hall.

Erdem, D. (2011). Türkiye'de 2005-2006 yılları arasında yayımlanan eğitim bilimleri dergilerindeki makalelerin bazı özellikler açısından incelenmesi: betimsel bir analiz. Eğitimde ve Psikolojide Ölçme ve Değerlendirme Dergisi, 2(1), 140-147.

Fraenkel, J. R., \& Wallen, N. E. (2006). How to design and evaluate research in education. New York: Mc Grawall Hill.

Karakütük, K. (2009). Lisansüstü eğitimde öncü bir kuruluş: Ankara Üniversitesi Eğitim (Bilimleri) Fakültesi (19691982). Prof. Dr. Ali Naim İnan'a Armağan. Yayına Hazırlayanlar: Mehmet Ünal, Veysel Başpınar, Hasan Seçkin Ozanoğlu ve Süleyman Yılmaz. Ankara: Seçkin Yayınevi.

Küçükoğlu, A. ve Ozan, C. (2013). Sınıf öğretmenliği alanındaki lisansüstü tezlere yönelik bir içerik analizi. Uluslararası Avrasya Sosyal Bilimler Dergisi, 4(12),28-47.

Miles, M. B. \& Huberman, A. M. (1994). An Expanded Sourcebook Qualitative Data Analysis (Second Edition). California: Sage Pablications, Inc.

Özenç, M. ve Özenç, E. G. (2013). Sınıf öğretmenleri ile yapılan lisansüstü eğitim tezlerinin yöntem bölümü açısından incelenmesi. Abant İzzet Baysal Üniversitesi Eğitim Fakültesi Dergisi, 13(1),132-141.

Palys, T. (2008). Basic research. The sage encyclopedia of qualitative research methods. California: Sage Publication

Patton, M. Q. (2002). Qualitative research \& evaluation methods (3rd Edition). California: Sage Publications.

Sağlam, M. (2007). Lisanüstü eğitim modelleri. Anadolu Üniversitesi Eğitim Bilimleri Enstitüsü Lisansüstü Eğitim Sempozyumu: Lisansüstü Eğitimde Sorunlar ve Çözüm Önerileri (17-20 Ekim 2007). (1-12). Eskişehir.

Şahin, D., Calp, Ş., Bulut, P. ve Kuşdemir, Y. (2013). Sınıf öğretmenliği eğitimi bilim dalında yapılmış lisansüstü tezlerin çeşitli kriterlere göre incelenmesi. Journal of World of Turks, 5(3), 187-205.

Terzi, A. R. (2005). Üniversite öğrencilerinin bilimsel epistemolojik inançları üzerine bir araştırma. Afyon Kocatepe Üniversitesi Sosyal Bilimler Dergisi, 7(2), 298-311.

Yıldırım, A. ve Şimşek, H. (2013). Sosyal bilimlerde nitel araştırma yöntemleri. Ankara: Seçkin Yayınevi. 
Extended Abstract

\section{Introduction}

The recent increase in the number of universities in our country has led to an increase in the demand for postgraduate education and brought along many scientific research pieces (Özenç \& Özenç, 2013). Master's and doctoral theses prepared in this sense have been seen as the most important scientific outputs of postgraduate education programs. The framework of postgraduate education programs has expanded further over time. It has also affected the education dimension and gave a positive momentum for the preparation of theses in classroom teaching included in primary education and the analysis of many dimensions, variables, new models, methods, and resources in classroom teaching, adding them to the literature. Therefore, these theses' purposes, scientific outlines of the research processes, evaluation methods, and criteria have gained importance.

The general evaluation of these studies accumulated in the literature over time provided information about the nature of past studies and shed light on future studies (Erdem, 2011; Küçükoğlu \& Ozan, 2013). In this context, analyzing the theses prepared in Turkey in classroom teaching and providing a general framework for them constitutes the study's main objective. In line with this objective, the postgraduate theses performed in the primary school teaching department between 2015 and 2020 were analyzed according to preparation year, the gender of the researcher, discipline, postgraduate level (master or doctorate), sample, data collection tools, and variables used in data analysis.

\section{Method}

This research, which is based on the analysis of postgraduate theses made in classroom teaching, was designed according to the qualitative approach. The document analysis method of qualitative approach was applied in this study; the analysis of the postgraduate theses in classroom teaching was performed by document analysis. For this, postgraduate theses in classroom teaching were accessed, and related documents were obtained. The sample of the research consisted of postgraduate theses in classroom teaching. Criterion sampling technique, one of the purposeful sampling methods, was used in determining the study's sample. In this framework, the research's basic criterion was specified as all postgraduate theses (with permission) prepared in classroom teaching within the postgraduate thesis's framework. In this regard, a total of 744 theses were evaluated.

Data of the study were collected from the access address of the National Thesis Center. The thesis review form created by the researchers according to the objectives of the research was used in the analysis of the theses. The data were analyzed through document analysis, during which eight analysis steps discussed by Fraenkel and Wallen (2006) were applied. First, relevant codes and themes were created for the theses, and then an expert evaluated these codes and themes. Each theme's findings are presented in tables as frequency $(\mathrm{f})$ and percentage $(\%)$.

\section{Findings}

Regarding the findings of the research, the majority of the prepared theses are master's theses. According to the gender distribution, more women are on the master's level, whereas men are more on the doctoral level. Regarding the distribution of postgraduate theses according to universities, Necmettin Erbakan University has a higher rate than other universities in master's theses, and Gazi University has a higher rate in doctoral theses. According to the disciplines, most master's and doctoral theses are grouped under the "Other" discipline (educational management, program development, guidance, psychological counseling, etc.). Regarding the theses in terms of advisor titles, the number of theses whose advisor has "Assoc. Dr." title is higher in the master's theses, whereas "Prof. Dr." title is more frequent in doctoral dissertations. Regarding the last five years in terms of thesis preparation, more theses were created at the master and doctoral levels in 2019 compared to other years. Regarding the samples on which the theses have focused, "Other (preschool, middle school, high school, teacher candidates, special education students)" and "4th grades" have been observed.

The evaluation of the prepared theses in terms of the methods used revealed that the quantitative method is preferred at the master level, followed by the qualitative method. Regarding the methods of doctoral dissertations, 
researchers preferred the mixed method in their studies, followed by the qualitative method. The most preferred data collection tools used in the theses at the master level are scale, interview, other, and document. The most preferred data collection tools in theses prepared at the doctoral level are interview, scale, observation, and test. Regarding the analysis methods applied in the master's theses, the frequency and percentages are given in the theses employing descriptive method as the quantitative method. The review of the descriptive analyzes used in the quantitative method shows that t-test, ANOVA, Mann Whitney, correlation, and reliability analysis are the most preferred tools.

Regarding the analysis used in the qualitative method, content analysis, and descriptive analysis are found to be the most used ones, followed by continuous comparative analysis, discourse analysis, and meta-analysis. The arithmetic mean value is the most preferred quantitative descriptive statistics used in theses prepared at the doctoral level. T-test, ANOVA, Mann-Whitney U, and Wilcoxon test were also preferred in the quantitative method's descriptive analysis. Regarding the qualitative dimension, the most applied approaches are content analysis and descriptive analysis, followed by system analytical analysis and discourse analysis.

\section{Result and Discussion}

In this study, in which the document analysis method was applied within the qualitative approach framework, the following results were obtained: most postgraduate theses are master's theses. This result is similar to the study of Şahin, Calp, Bulut, and Kuşdemir (2013). Regarding the samples of the theses included in the study, more studies were carried out with "preschool, secondary school, high school, teacher candidates, special education students." This result is in line with the grades on which the theses have focused. Concerning the grade level, it was concluded that fewer studies were performed at $1^{\text {st }}, 2^{\text {nd }}, 3^{\text {rd, }}$ and $4^{\text {th }}$ grade of the primary school, which are important for classroom teaching.

Regarding the methods used in the theses, most of the master's theses were carried out using a quantitative method, whereas mixed methods were mostly employed in doctoral theses. This result is similar to the Küçükoğlu and Ozan (2013) study. According to the data collection tools used in the theses, scales were more preferred in master's theses, and the interview technique was more used in doctoral dissertations. This result is similar to the Küçükoğlu and Ozan (2013) study.

Based on these results, the following suggestions can be submitted: more doctoral programs should be opened to increase doctoral dissertations in classroom teaching. Studies in the department of classroom education should be increased in line with associate professorship disciplines. In master's thesis studies, emphasis should be put on mixed methods, in which both quantitative and qualitative methods are used. The theses involving 1st, 2nd, 3rd, and 4th grades should be increased in master and doctoral theses. More advanced statistical methods should be used in the quantitative analysis of the theses to be performed. Different qualitative analysis methods should be applied (Discourse analysis, ethnographic, phenomenology, etc.)

\section{Araştırmanın Etik Taahhüt Metni}

Yapılan bu çalışmada bilimsel, etik ve alıntı kurallarına uyulduğu; toplanan veriler üzerinde herhangi bir tahrifatın yapılmadı̆̆ıı, karşılaşılacak tüm etik ihlallerde "Manisa Celal Bayar Üniversitesi Eğitim Fakültesi Dergisi ve Editörünün” hiçbir sorumluluğunun olmadığı, tüm sorumluluğun Sorumlu Yazara ait olduğu ve bu çalışmanın herhangi başka bir akademik yayın ortamına değerlendirme için gönderilmemiş olduğu sorumlu yazar tarafından taahhüt edilmiştir. 